\title{
Wave-induced variability of the underwater light climate in the littoral zone
}

\author{
Hilmar Hofmann, Andreas Lorke and Frank Peeters
}

\section{Introduction}

Underwater irradiance, here referred to as photosynthetically active radiation (PAR), undergoes strong temporal fluctuations. These fluctuations are not only caused by variations in the incoming light intensity but also by variations in the elevation and curvature of the water surface resulting from wave motion (SNyder \& Dera 1970, Kirk 1994, Zaneveld et al. 2001). In addition, wave-induced resuspension of particles in the littoral zone can cause rapid changes of light attenuation within the water column. Thus, the variability of the light field is maximal at shallow depths (Dera \& Gordon 1968, RørsletT et al. 1997, SchUBERT et al. 2001). Light intensity is important for the growth of phytoplankton (FINGER et al. 2007), biofilms, and macrophytes (SCHEFFER et al. 1993) and affects habitat choice, food uptake, and predation pressure of fishes (UTNEPalm 2004, Schleuter \& Eckmann 2006). The biological relevance of fluctuating light is not only determined by the intensity of the fluctuations, but also by temporal scales (WALSH \& Legendre 1983, Pahl-Wostl 1992).

We experimentally investigated the variability of the underwater light climate in the littoral zone with the intension of providing amplitudes and temporal scales of the intensity fluctuations resulting from wave focussing, change in surface elevation and resuspension.

Key words: light climate, resuspension, shallow waters, surface waves, temporal variability, wave focussing

\section{Materials and methods}

Study site

Lake Constance, the second largest (in surface area, $536 \mathrm{~km} 2$ ) prealpine lake in Europe, is located in the southwest of Germany and borders Switzerland and Austria. The littoral zone covers about $10 \%$ of the total surface area (BRAUN \& SCHÄRPF 1990). Measurements were carried out in the western part of Upper Lake Constance at a site called Littoral Garden (LG; $\left.47^{\circ} 41^{\prime} 29^{\prime} \mathrm{N}, 09^{\circ} 12^{\prime} 11^{\prime \prime} \mathrm{E}\right)$. The shore is exposed to a highly variable surface wave field, which is dominated by wind waves in winter and ship waves in summer (HofmanN et al. 2008a). Ship waves stem from a close by ferry track with regular sailings throughout the year, from passenger ships travelling parallel to the shoreline during the tourist season (mid-March to mid-October), and from a newly introduced catamaran ferry.

\section{Instrumentation}

The underwater light climate was measured with high temporal resolution $(128 \mathrm{~Hz})$ by a chain of 6 synchronised spherical PAR sensors (LI-193SA, LI-COR) combined with a pressure sensor (PS; PDCR 1730, DRUCK). The PS has an accuracy of $0.1 \mathrm{mbar}$, sufficient to resolve wave heights down to $0.01 \mathrm{~m}$ and wave frequencies up to $2 \mathrm{~Hz}$ corresponding to wave lengths down to $0.4 \mathrm{~m}$, if the sensor is positioned $0.2 \mathrm{~m}$ below the water surface at $2 \mathrm{~m}$ water depth. The 6 spherical PAR sensors measure scalar irradiance with a response time of $10 \mu \mathrm{s}$.

Measurements were conducted between 18 April and 04 May 2007 at a water depth of $2.2 \mathrm{~m}$. All sensors were attached to a bottom-resting pole. One of the light sensors ( $\mathrm{S}$ 0) was placed $0.4 \mathrm{~m}$ above the water surface as a reference, measuring the incident light. The other 5 PAR sensors were mounted at 0.2 (S 1), 0.7 (S 2), 1.2 (S 3), 1.7 (S 4), and $2.0 \mathrm{~m}$ (S 5) below the water surface (Fig. 1). The pressure sensor was deployed next to $\mathrm{S} 1$.

\section{Analysis}

The measured time series of subsurface pressure was converted to a time series of surface elevation using the procedure described in Hofmann et al. (2008a).

Power spectra of light intensity and surface elevation were estimated by calculating power spectra from segments of the time series consisting of 8192 samples $(\sim 1.1 \mathrm{~min})$ with $50 \%$ overlap and subsequent averaging of 56 consecutive spectra to reduce confidence intervals.

The amplitude of the fluctuations in the underwater light field as a function of depth was estimated from the 5 sub- 


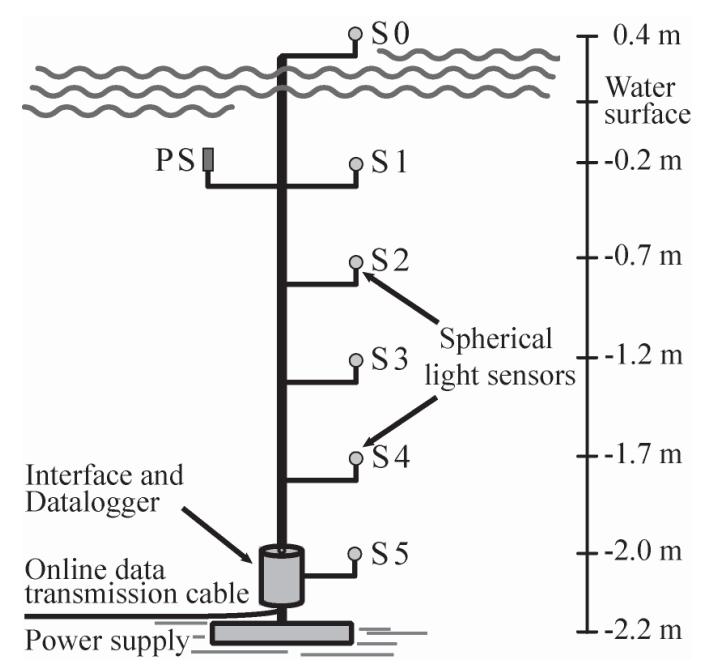

Fig. 1. Schematic sketch of the light chain deployed in the littoral zone of Lake Constance (PS: pressure sensor; S $0-\mathrm{S} 5$ : PAR sensors).

merged light sensors by calculating the minimum and the maximum light intensities within 10-s time intervals. The mean and the standard deviation of the respective minima and maxima were calculated for one-hr time periods.

The effect of surface elevation on light intensity was estimated from Lambert-Beer's-Law. Assuming exponential decay of light with depth, hourly mean light intensities at 2 neighbouring light sensors were used to determine the light attenuation coefficient $(\mathrm{Kd})$ for the respective depth range. Then, the surface elevation derived from the pressure sensor data was used together with the $\mathrm{Kd}$ values to calculate the fluctuations in light intensity due to fluctuations in surface elevation.

\section{Results and discussion}

\section{Amplitudes of underwater light fluctuations}

Data from the 19 April 2007 were chosen to elucidate the features of the underwater light climate on cloudless days with bright sunlight. Between 10:00 and 11:00 h, the measured incident light intensity did not fluctuate significantly, whereas the underwater irradiance showed fluctuations with high amplitudes and high frequencies at all depths. The highest amplitudes occurred near the surface. Between 10:31:30 and 10:32:00 $\mathrm{h}$ at $0.2 \mathrm{~m}$ below the surface (S 1), the light intensity fluctuated between +700 and $-600 \mu \mathrm{mol}$ quanta $\mathrm{s}^{-1} \mathrm{~m}^{-2}$ around its mean value of $1684 \mu \mathrm{mol}$ quanta $\mathrm{s}^{-1} \mathrm{~m}^{-2}$ (Fig. 2A), which indicates that the fluctuations are biased toward higher intensities due to nonlinear refractive effects at the water surface (Stramski \& Legendre 1992). During this time period, the surface wave field was characterised by small-ampli- tude $(0.01-0.05 \mathrm{~m})$, high-frequency $(1-2 \mathrm{~Hz})$, shortlength $(0.4-1.6 \mathrm{~m})$ wind waves (ripple waves) and a ship wave group with a maximum height of about $0.3 \mathrm{~m}$ (Fig. 2B). The ripple waves are known to induce wave focussing (SNyder \& Dera 1970, Rørslett et al. 1997), whereas the ship waves with a period of $2.9 \mathrm{~s}$ and a wave length of $13 \mathrm{~m}$ essentially lead to an elevation of the water surface and not to a pronounced focussing effect of the incident light (Rørslett et al. 1997, Stramska \& Dickey 1998). The effect of the change in surface elevation on the near surface light climate was recorded (Fig. 2B). The 1-s running average of the $\mathrm{S} 1$ time series shows a periodically fluctuating light intensity that is phase shifted by $180^{\circ}$ relative to the oscillation of the surface elevation. The amplitude of the oscillating light intensity is about $\pm 70 \mu \mathrm{mol}$ quanta $\mathrm{s}^{-1} \mathrm{~m}^{-2}$, which is small, compared to the total fluctuation of the light intensity. The difference between the total fluctuation in light intensity (Fig. 2A) and the light fluctuation due to the surface elevation (Fig. 2B) can be attributed to the effect of wave focussing and ranges between +40 and $-35 \%$ of the mean light intensity. The effect of surface elevation contributes only about $\pm 5 \%$ to the overall fluctuation in light intensity (Fig. 2C). Clearly, extreme values of light intensity fluctuations are dominated by the effects of wave focussing. SCHUBERT et al. (2001) and RøRSLETT et al. (1997) have demonstrated that wave focussing can cause light intensities significantly above the incident light intensity, reaching up to 5 times the mean. These extremely high light intensities were observed with small planar sensors that measure only downwelling irradiance and thus differ from the spherical sensors used in this study that integrate light from all directions.

The vertical distribution of the range of the underwater fluctuations in the light intensities due to wave focussing and due to ship-wave induced surface elevation (Fig. 3) shows the minima and maxima of the light intensities at $0.2,0.7,1.2,1.7$, and $2.0 \mathrm{~m}$ below the surface measured on 19 April 2007 between 10:00 and 11:00 h. At all depths the amplitudes of light intensity fluctuations caused by wave focussing are much larger than those caused by the elevation of the surface alone. The mean light intensity, centred within the intensity range due to surface elevation, decreased monotonously with depth from about $1680 \mu \mathrm{mol}$ quanta $\mathrm{s}^{-1} \mathrm{~m}^{-2}$ at $0.2 \mathrm{~m}$ to about $960 \mu \mathrm{mol}$ quanta $\mathrm{s}^{-1} \mathrm{~m}^{-2}$ at $2.0 \mathrm{~m}$ below the surface. In contrast, the maximum light intensities resulting from wave focussing did not monotonously decrease with depth: the maximum range $\left(1400 \mu \mathrm{mol}\right.$ quanta $\left.\mathrm{s}^{-1} \mathrm{~m}^{-2}\right)$ and the highest maximum values in light intensity $\left(2750 \mu \mathrm{mol}\right.$ quanta $\left.\mathrm{s}^{-1} \mathrm{~m}^{-2}\right)$ were observed at $0.7 \mathrm{~m}$ and not at $0.2 \mathrm{~m}$ depth. Further, the data indicate that the fluctuations of the light intensity 
Fig. 2. Amplitudes of the near surface underwater light field and the simultaneously measured surface elevation on 19 April 2007 between 10:31:30 and 10:32:00 h. (A) Absolute fluctuations of the light intensity about its mean value at $\mathrm{S} 1(0.2 \mathrm{~m}$ below the surface). The mean value was calculated for the time period specified above. (B) Surface elevation (generated by a ship wave, bold solid black line) and related absolute fluctuations of the light intensity (fine solid grey line) derived by applying a 1-s running average on the times series of S 1. (C) Relative fluctuations of the light intensity (fine solid grey line) and of the surface elevation (bold solid black line). The relative change of the light intensity caused by surface elevation at $0.2 \mathrm{~m}$ below the surface was calculated for an exponential decay of light with depth using the average attenuation coefficient $(\mathrm{Kd})$ between $\mathrm{S} 1$ and $\mathrm{S} 2$ of $0.35 \mathrm{~m}^{-1}$.

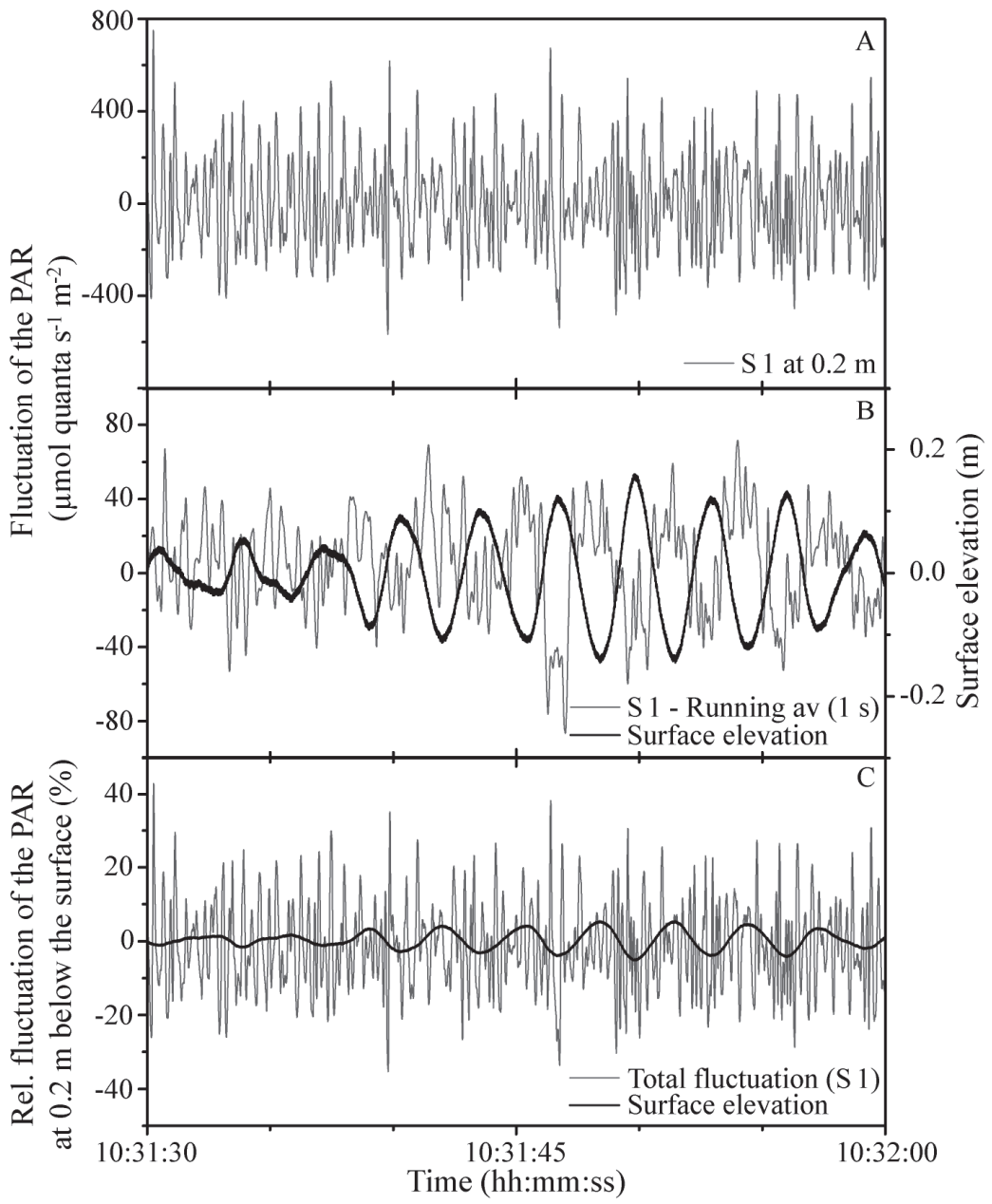

are asymmetrical around the mean, with positive deviations from the mean being larger than negative deviations at all depths (Fig. 3). Such a vertical distribution of the near surface underwater light field was also observed by SNyder \& Dera (1970), but detailed measurements of the surface wave field were not available. ZANEVELD et al. (2001) investigated the consequences of wave focussing on light intensities from a theoretical perspective. Assuming a modulated surface wave field consisting of lowfrequency as well as high-frequency waves with different wave heights, they demonstrated that the maximum in light intensity is shifted from the surface to larger depths. This shift occurs because of the position of the first focal point owing to the lens effect of surface waves. The depth and the intensity of the maximum value in the light intensity are highly dependent on the composition of the surface wave field. Low-frequency waves shift the maximum in light intensity to larger depths, whereas high-frequency waves result in a maximum at shallower depths and cause higher maximal intensities. Our measurements can partly confirm these theoretical considerations, but detailed measurements with a higher spatial resolution near the water surface are needed to demonstrate the shift of the maximum in light intensity under changing properties of the surface wave field.

\section{Temporal scales of underwater light fluctuations in relation to the surface wave field}

Spectral analysis of the light intensity at S 1 and of the surface elevation (derived from the pressure sensor) time series on 19 April 2007 for the time periods between 10:00 and 11:00 h (first hour) and 13:00 and 14:00 h (second hour) reveals a clear linkage between the surface wave field and the underwater light field (Fig. 4). During both time periods, spectra of the light intensity show peaks at $0.27 \mathrm{~Hz}$ and between 0.5 and $0.6 \mathrm{~Hz}$. Between 13:00 and 14:00 $\mathrm{h}$ the peaks are more pronounced, and an additional peak at $0.35 \mathrm{~Hz}$ appears in the spectrum of light intensity (Fig. 4A). The occurrence of these peaks is related to the low-frequency surface waves found also in 


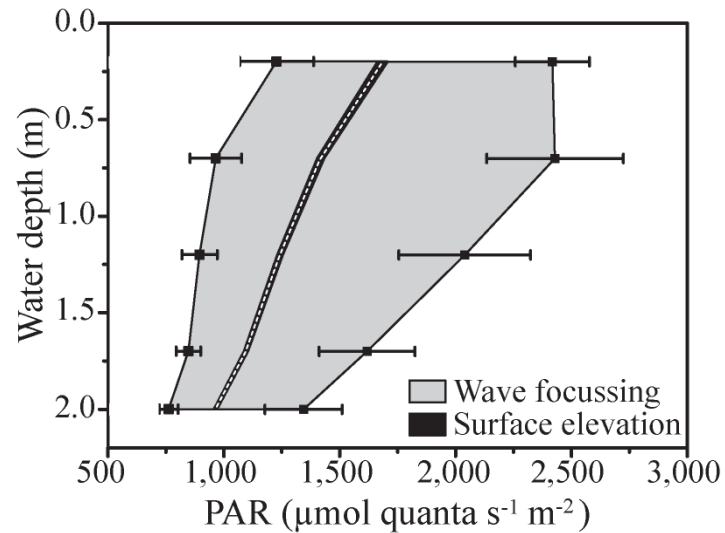

Fig. 3. Amplitudes of the fluctuations in the underwater light field as function of depth caused by the effect of wave focussing (grey area) and solely by the effect of surface elevation (black area) on 19 April 2007 between 10:00 and 11:00 h. Symbols (filled squares) show the mean values of the minimum and the maximum light intensities within $10 \mathrm{~s}$ time intervals with their standard deviation (not shown for the effect of surface elevation to keep graphical clarity). The overall mean of the measured light intensity is shown by the white dashed line. The effect of surface elevation on light intensity was estimated from Lambert-Beer's-Law. Assuming exponential decay of light with depth, hourly mean light intensities at neighbouring light sensors were used to estimate the light attenuation coefficient $(\mathrm{Kd})$ for the respective depth range. These attenuation coefficients in combination with surface elevation derived from the pressure sensor data were used to estimate the fluctuation in light intensity due to fluctuations in surface elevation as described above.

the spectra of surface elevation (Fig. 4B). The peaks at $0.27,0.35$, and $0.5-0.6 \mathrm{~Hz}$ are due to surface waves generated by ferries, passenger ships, and wind, respectively (Hofmann 2008b). During the 2 hours considered (Fig. 4 ), these wind and ship waves had wave heights between 0.05 and $0.3 \mathrm{~m}$, which are sufficient to significantly affect the near surface underwater light climate. The peak at $0.16 \mathrm{~Hz}$ in the surface elevation spectrum (Fig. 4B) can be attributed to waves from the catamaran ferry. This peak is not resolved in the spectra of the light intensity (Fig. 4A) because the wave height resulting from the catamaran at site $\mathrm{LG}$ is too small $(<0.05 \mathrm{~m})$ to induce a substantial variance in the light intensity. In addition to the peaks described above, the spectrum of the light intensity from the first hour shows a broad peak between 1.2 and $4 \mathrm{~Hz}$, which is narrower and less pronounced in the spectrum for the second hour. The latter spectrum has a small peak around $2.5 \mathrm{~Hz}$ with a spectral density, which is 2 orders of magnitude lower than that of the broad peak in the spectrum from the first hour (Fig. 4A). The variance of

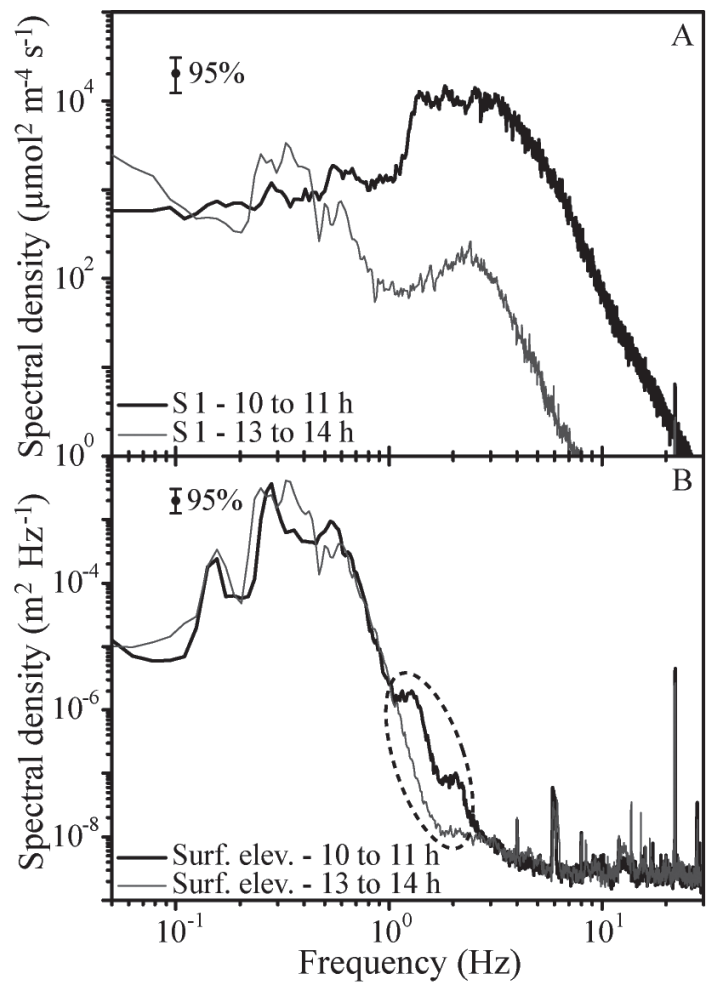

Fig. 4. Spectra of the light sensor $\mathrm{S} 1$ (A) and the pressure sensor (PS, surface elevation) (B) at $0.2 \mathrm{~m}$ below the surface on 19 April 2007 between 10:00 and 11:00 h (bold solid black line), and 13:00 and 14:00 $\mathrm{h}$ (fine solid grey line). The spectra were estimated from the light and surface elevation time series over the respective hour using segments of 8192 samples ( $\sim 1.1 \mathrm{~min})$ and subsequent averaging. The ellipse in the spectrum of the pressure sensor (panel B) emphasises peaks around frequencies of 1.5 and $2 \mathrm{~Hz}$, which were observed between 10:00 and 11:00 h but not between 13:00 and 14:00 h. These peaks can be attributed to the occurrence of ripple waves and correspond directly to the observed peaks in the spectrum of light intensity fluctuations (panel A). The spikes above $3 \mathrm{~Hz}$ in the spectra of surface elevation are artefacts of the PS.

the light intensity at frequencies above $1 \mathrm{~Hz}$ can be most likely attributed to the effect of wave focussing.

As the spectra of light intensity, the spectra of surface elevation from the 2 hours also differ in the high-frequency range between 1 and $2 \mathrm{~Hz}$. During the first hour, peaks were observed at 1.5 and $2.0 \mathrm{~Hz}$, which are not visible in the spectrum from the second hour (Fig. 4B, dashed ellipse). These peaks can be attributed to ripple waves (described above). The coincidence of these ripple waves and the strong fluctuation in light intensity resulting from light focussing suggests that light focussing is predominantly connected to the occurrence of small ripple waves because wave focussing was pronounced dur- 
ing the first hour and was nearly absent during the second hour.

At frequencies above $2 \mathrm{~Hz}$, the spectra of surface elevation do not show variance except for noise and instrumental resonance signals from the pressure sensor. At frequencies above $2 \mathrm{~Hz}$ surface waves have wave lengths $<0.4 \mathrm{~m}$. Pressure fluctuations from these waves attenuate rapidly with increasing depth and cannot be resolved by our pressure sensor.

In addition to fluctuations in light intensity (with periods below a few seconds due to wave-induced surface elevation and light focussing), light intensity in the littoral zone is affected by suspended particles resulting from wave-induced resuspension (ERm \& SoOmere 2006, HofMANN et al. 2008a) at time periods ranging from minutes to hours, and even up to seasonal fluctuations. During time periods with resuspension, the light intensities at 2 $m$ depth decreased substantially by up to $70 \%$, depending on the particle concentration in the water column. Light attenuation calculated from the PAR sensor chain typically increased over the course of the day because shipwave induced resuspension leads to an increase of the suspended particle load. Note that resuspension by ship waves is much more intense during daytime than at night because of increased ship traffic and larger wave heights during daytime (Hofmann et al. 2008a).

More important than the diurnal fluctuation in light attenuation is the daily cycle of incident light, which leads to a strong daily cycle in the underwater light intensity. On seasonal time scales, not only the seasonal variation in the incident light (about $25 \%$ between winter and summer at Lake Constance, latitude $47.7^{\circ}$ ), but also water level fluctuations, which are about $2-3 \mathrm{~m}$ at Lake Constance (HoFmann et al. 2008b), alter the underwater light climate for sessile organisms and biofilms. For a typical $\mathrm{Kd}$ for Lake Constance of $0.35 \mathrm{~m}^{-1}$, the seasonal variation of the incident light would have the same effect as a change in water level of about $0.8 \mathrm{~m}$. Thus the fluctuations of the light intensity induced by the water level fluctuations have larger amplitudes than seasonal variation of the incident light. Because of high water levels in summer and low in winter, where the incident light reaches its maximum and minimum, respectively, both processes counteract and reduce the amplitudes in the variation of the underwater light intensity for sessile organisms.

\section{Conclusions}

Fluctuations of the underwater light intensity caused by surface waves due to surface elevations were distin- guished from those due to focussing and defocusing of the incident sunlight (wave focussing) by using synchronised high-frequency measurements of photosynthetically active radiation (PAR) and pressure. In general, PAR showed high-amplitude and high-frequency fluctuations near the surface (0.2-2.0 m depth). Strongest fluctuations were observed under bright sun when the surface wave field was dominated by small ripple waves. Under such conditions the amplitudes of the fluctuations in the light intensity due to wave focussing are much larger than that of the surface elevation caused by wind and ship waves. Further, wave focusing shifts the maximum of the underwater light intensity to greater depths, depending on the properties of the surface wave field.

The resuspension of particles induced by wind and ship waves can dramatically reduce the light intensity in the littoral zone on temporal scales ranging from minutes to hours and thus may contribute to light limitation of phytoplankton and biofilm growth.

\section{Acknowledgements}

We thank Georg Heine and his colleagues from the electronic and mechanical workshop at the University of Konstanz for technical assistance and for the development of the light chain. Special thanks to Dr. R. Kipfer for his support with the instrumentation. We gratefully acknowledge the help of the technical staff at the Limnological Institute, Tobias Merz, and Matthias Kohlndorfer during fieldwork and data analysis. This work was supported by the German Research Foundation (DFG) within the framework of the Collaborative Research Center 454 "Littoral Zone of Lake Constance" and by the European Science Foundation (ESF) with a travel grant.

\section{References}

Braun, E. \& K. SchÄrpf. 1990. Internationale Bodensee-Tiefenvermessung, p. 98. IGKB - Internationale Gewässerschutzkommission für den Bodensee.

Dera, J. \& H.R. Gordon. 1968. Light fluctuations in the photic zone. Limnol. Oceanogr. 13: 697-699.

Erm, A. \& T. Soomere. 2006. The impact of fast ferry traffic on underwater optics and sediment resuspension. Oceanologia (suppl.) 48: 283-301.

Finger, D., P. Bossard, M. Schmid, L. Jaun, B. Müller, D. Steiner, E. Schäffer, M. Zeh \& A. WÜEst. 2007. Effects of alpine hydropower operations on primary production in a downstream lake. Aquat. Sci. 69: 240-256, doi:10.1007/ s00027-007-0873-6.

Hofmann, H., A. Lorke \& F. Peeters. 2008a. The relative importance of wind and ship waves in the littoral zone of a large lake. Limnol. Oceanogr. 53: 368-380. 
Hofmann, H., A. Lorke \& F. Peeters. 2007b. Temporal and spatial scales of water level fluctuations in lakes and their ecological implications. Hydrobiol. (subm.).

KIRK, J.T.O. 1994. Light and photosynthesis in aquatic ecosystems. 2nd ed. Cambridge Univ. Press.

Pahl-Wostl, C. 1992. Dynamic versus static models for photosynthesis. Hydrobiol. 238: 189-196.

Rørslett, B., I. Hawes \& A.M. Schwarz. 1997. Features of the underwater light climate just below the surface in some New Zealand inland waters. Freshw. Biol. 37: 441-454.

Scheffer, M., S.H. Hosper, M.-L. Meijer, B. Moss \& E. JeppeSEN. 1993. Alternative equilibria in shallow lakes. Trends Ecol. Evol. 8: 275-279.

Schleuter, D. \& R. Eckmann. 2006. Competition between perch (Perca fluviatilis) and ruffe (Gymnocephalus cernuus): the advantage of turning night into day. Freshw. Biol. 51: 287-297, doi:10.1111/j.1365-2427.2005.01495.x.

Schubert, H., S. SAgert \& R.M. Forster. 2001. Evaluation of the different levels of variability in the underwater light field of a shallow estuary. Helgol. Mar. Res. 55: 12-55, doi:10.1007/s10150000064.
Snyder, R.L. \& J. DerA. 1970. Wave-induced light-field fluctuations in the sea. J. Opt. Soc. Am. 60: 1072-1079.

Stramska, M. \& T. Dickey. 1998. Short-term variability of the underwater light field in the oligothrophic ocean in response to surface waves and clouds. Deep Sea Res. Part I 45: 1393-1410.

Stramski, D. \& L. Legendre. 1992. Laboratory simulation of light-focusing by water-surface waves. Mar. Biol. 114: 341348.

Utne-Palm, A.C. 2004. Effects of larvae ontogeny, turbidity, and turbulence on prey attack rate and swimming activity of Atlantic herring larvae. J. Exp. Mar. Bio. Ecol. 310: 147161.

Walsh, P. \& L. Legendre. 1983. Photosynthesis of natural phytoplankton under high frequency light fluctuations simulating those induced by sea surface waves. Limnol. Oceanogr. 28: $688-697$.

Zaneveld, R.J.V., E. Boss \& A. Barnard. 2001. Influence of surface waves on measured and modeled irradiance profiles. Appl. Opt. 40: 1442-1449.

Authors' address: H. Hofmann, A. Lorke, F. Peeters, Environmental Physics Group, Limnological Institute, University of Konstanz, Mainaustr. 252, D-78465, Konstanz, Germany. E-mail: hilmar.hofmann@uni-konstanz.de 